\title{
RETRACTED ARTICLE: Gradually varied flow computation in channel networks by adaptive algorithm
}

\author{
MOHAMMAD JAHANDAR MALEKABADI ${ }^{1, *}$, FARHOUD KALATEH $^{1}$ and \\ S MURTY BHALLAMUDI ${ }^{2}$ \\ ${ }^{1}$ Department of Civil Hydraulics Engineering, University of Tabriz, Tabriz, Iran \\ ${ }^{2}$ Department of Civil Engineering, Indian Institute of Technology Madras, Chennai 600036, India \\ e-mail:m.jahandar69@yahoo.com; fkalateh@tabrizu.ac.ir; bsm@civil.iitm.ernet.in
}

MS received 20 August 2016; revised 17 November 2016; accepted 25 November 2016; published online 5 April 2017

The article "Gradually varied flow computation in channel networks by adaptive algorithm" (DOI 10.1007/s12046017-0640-x) which has been published online has been retracted by Chief Editor of the journal Sadhana as per the Committee on Publication Ethics (COPE) guidelines on redundant publication. The retraction is due to submitting the paper to the journal Sadhana without the consent or knowledge of one of the authors (S Murty Bhallamudi) and also after thorough investigation it has been found that the content is partially plagiarized from the article previously published: DOI: 10.1061/(ASCE)0733-9437(2004)130: $5(424)$, titled "Gradually varied flow computation in cyclic looped channel networks" by H Prashanth Reddy and S Murty Bhallamudi, Journal of Irrigation and Drainage Engineering, (copyright) ASCE, September/October 2004, pp. 424-431.

Electronic supplementary material The online version of this article (doi:10.1007/s12046-017-0640-x) contains supplementary material, which is available to authorized users.

*For correspondence 